\title{
Daño emergente por perjuicio sobre mascotas o animales de compañía. Comentario a la sentencia de la Corte de Apelaciones de Valparaíso de 13 de diciembre de 2018 , dictada en causa Rol $^{\circ}$
}

\section{1-2018}

\section{David Alejandro Rodríguez Guerra ${ }^{1}$ \\ Universidad Diego Portales, Chile}

Ante el $1^{\circ}$ Juzgado Civil de Quilpué la demandante dedujo demanda de indemnización de perjuicios por responsabilidad contractual contra la veterinaria de sus gatos, llamados “Tony" y "Junior", solicitando la suma de \$20.0oo por daño emergente y \$5.000.00o por daño moral. Fundó su demanda indicando que para fiestas patrias tuvo que realizar un viaje, por lo que dejó a sus gatos en una guardería a cargo de la demandada. Señala que al momento de ir a recoger a sus mascotas, tan solo le devuelven a Junior y le informan que Tony no aparecía, para luego notar que su canil estaba roto y con la puerta abierta. La demandada se defendió indicando que su guardería tenía una política familiar y que guardan a las mascotas en piezas sin caniles y pese a los temores que tenía la demandante respecto de que las puertas y ventanas de la habitación quedaran abiertas, igualmente accedió a los servicios prestados, por lo que también hay responsabilidad de ella. Por tanto, no le corresponde responder por el daño moral. Agrega que en caso de estimarse lo contrario, la cuantía es excesiva, toda vez que hizo los mayores esfuerzos por encontrar al gato y no lo logró. Así mismo, la demandada dedujo demanda reconvencional solicitando \$3.0oo.ooo por daño moral y \$2.00o.ooo por daño emergente atendido que una de las hijas de la dueña de Tony comenzó a desprestigiar a la demandante reconvencional a través de redes sociales, cumpliéndose todos los requisitos de la responsabilidad extracontractual. La dueña y demandada reconvencional contesta indicando que los mensajes fueron emitidos por

1. Licenciado en Ciencias Jurídicas y Sociales y Magíster en Derecho Civil Patrimonial ambos de la Universidad Diego Portales y Ayudante Novel del Departamento de Derecho de los Negocios de la Facultad de Derecho de la Universidad Diego Portales. E-mail: david.rodriguezg@mail.udp.cl. 
su hija quien es mayor de edad y no vive bajo su dependencia, por lo que respecto de sí misma, no se cumple ningún requisito de la responsabilidad civil.

El Juzgado tuvo por acreditada la existencia de la obligación y la falta de restitución de la mascota, dando por probado el incumplimiento. Así mismo, desestimó la defensa de que hubo responsabilidad de la dueña por haber aceptado dejar a sus mascotas pese a sus temores. Acto seguido, el Juzgado tuvo por acreditado el daño emergente ascendente a $\$ 20.000$ por la no restitución de uno de sus gatos y que las probanzas resultaron insuficientes para demostrar la afectación sufrida por la demandante, por lo que se rechazó el daño moral solicitado. En cuanto a la demanda reconvencional, fue desestimada ya que se fundó por un acto de una hija de la demandante quien no es parte del juicio.

La dueña de los gatos, apeló de esta decisión para ante la Corte de Apelaciones de Valparaíso, la cual manifestó que los antecedentes aportados dejan de manifiesto la cercanía y cariño que para la actora tenía su gato, como asimismo, el significado emocional que este tenía para ella, toda vez que Tony tenía gran arraigo familiar ya que fue un regalo de su difunto marido, todo lo cual demuestra la magnitud del daño en el plano afectivo que le fue causado, el que, sin duda, debe ser indemnizado, declarando que se hace lugar al daño moral pedido en la suma de \$1.00o.ooo.

El presente trabajo tiene por objeto analizar el daño emergente sufrido por el dueño por ataques, muerte o extravío de su mascota, considerando que en este caso, el daño emergente solicitado se redujo únicamente al valor pagado por el servicio pactado y no por el valor de la mascota en sí misma.

La Ley $\mathrm{N}^{\circ} 21.020$ sobre tenencia responsable de mascotas y animales de compañía (en adelante "la Ley") ha definido con claridad lo que debe entenderse por tales. Así, la Ley expresa que son mascotas o animales de compañía "aquellos animales domésticos, cualquiera sea su especie, que sean mantenidos por las personas para fines de compañía o seguridad".

Aquello implica que un animal para ser mascota, debe necesariamente cumplir con la finalidad de acompañar o proveer seguridad a su dueño. De aquello se entiende, a contrario sensu, que si el animal cualquiera sea su especie, no tiene dichas finalidades, entonces no es una mascota.

Estas finalidades, parecen conferirles un carácter especial, puesto que en virtud de aquellas, los dueños podrían desarrollar intensos sentimientos de afecto, y se volverían lo que el Código Civil denomina bienes con valor de afección, en los términos planteados en los artículos 393 y 659 del Código Civil (en adelante "el Código"). En mi parecer, estos afectos, que derivan directamente de las finalidades que la Ley le reconoce a las mascotas, no deben ser olvidados al momento de cuantificar el daño emergente. Como manifiesta Stitchkin ${ }^{2}$, los afectos también son intereses protegidos 
por el ordenamiento jurídico, y por ello mismo pueden llegar a complicar la cuantificación del daño emergente en casos como el que se comenta.

Si lo anterior es cierto, entonces surgen problemas al momento de cuantificar el daño emergente en caso de que la mascota sea dañada. El problema recae en que avaluar económicamente a la mascota, parece necesariamente involucrar una avaluación del sentimiento de compañía y seguridad que este le proveía a su dueño. De acuerdo a Barros "Los daños patrimoniales tienen la ventaja de ser avaluables en dinero de acuerdo a criterios económicos que garantizan una cierta equivalencia entre el daño sufrido y su reparación. Por su naturaleza, tienen un valor de mercado: se trata de ventajas económicas que no se van a obtener, que constituyen un lucro cesante, o de gastos o pérdidas de valor de bienes, que dan lugar a un daño emergente" ${ }^{3}$. Sin embargo, en caso de que la pérdida sea una mascota ¿Cómo podría garantizarse la equivalencia entre el daño sufrido y su reparación?

De los hechos del caso se desprende que entre las partes existió un contrato innominado de guardería en favor de "Tony", quien fue extraviado por la demandada. La demandante al demandar el daño emergente tan solo demandó el valor pagado por el servicio, por un monto de \$20.00o. No demandó lucro cesante puesto que su gato era para compañía y no para obtener ventajas económicas, y tampoco demandó el daño emergente por el valor del gato como cosa en sí misma, presumiblemente porque al ser un bien con valor de afección, no pudo ponerle un precio como si fuera una cosa con estricto valor pecuniario. Por tanto, el único daño patrimonial demandado fue el daño emergente por el valor del servicio. Junto con ello, demandó el daño moral por la pérdida de su compañero felino, el cual fue concedido por un monto de \$1.00o.ooo.

De aquello puede inferirse que este contrato tenía un predominante interés extrapatrimonial. Aquello puede explicarse por el carácter de bien con valor de afección que tienen las mascotas. En palabras de Stitchkin podrían ser considerados bienes extrapatrimoniales ${ }^{4} \mathrm{y}$ un daño en ellos, genera principalmente daño extrapatrimonial y marginalmente daño patrimonial. Esto se debe a la extrema dificultad o moral imposibilidad de valorar pecuniariamente el valor de una mascota.

Sin embargo, si las mascotas estrictamente son cosas y son bienes, su avaluación pecuniaria bajo criterios de mercado debiese ser posible, por muy incómodo que resulte. Si bien es posible esgrimir que para algunos sus mascotas son inapreciables pecuniariamente, un daño en ellos puede ser entendido sin problemas como un empobrecimiento efectivo y una disminución real del patrimonio ${ }^{5}$. Con todo, la situación se complica cuando se recuerdan las finalidades de las mascotas. Parece ser, que valorar

3. BARROS (2006) p. 233.

4. STITCHKIN (1961) pp. 3-29.

5. SALINAS (2011) p. 377. 
económicamente a una mascota implica necesariamente valorar los sentimientos de compañía y seguridad, y aquello, en mi parecer, corresponde más bien a un interés extrapatrimonial. Aquello implica que la separación entre daño emergente y daño moral se torna difusa en caso de que lo dañado sea una mascota, complicando la identificación del tipo de daño y su cuantificación. Por ello, como en el caso en comento, es posible encontrarse con dueños incapacitados de valorar económicamente a su mascota y por tanto, renuncian a demandar daño emergente por el valor de la mascota en sí misma.

Pero en caso de encontrarnos con un dueño que efectivamente pretende demandar un daño emergente por el valor económico intrínseco de la mascota ¿Qué sucedería en el caso de que esta termina muerta o extraviada sin mediar contrato entre el dueño y quien mató o extravió a la mascota? ¿Qué sucedería si en vez de terminar muerta o extraviada, la mascota tan solo queda dañada?

Si no media un contrato entre las partes, y la mascota muere o se extravía por un acto del demandado, entonces no habría desembolso o gasto de dinero que corresponda a un daño emergente. El único daño emergente que podría solicitarse sería el valor económico de la mascota. En ese entendido, es posible enfrentarse con a lo menos dos casos.

Primero, podría presentarse el caso del dueño que con dificultad le otorga un valor a su mascota, pero junto con ello, pretende valorizar sus sentimientos de compañía y seguridad como si fueran también un daño emergente. En otros términos, se plantearía que la mascota, al servir de compañía y seguridad, en estricto rigor valdría para el dueño, más que el valor de mercado. Por ende, no correspondería valorarla tan solo por dicho valor. En mi parecer, dichos sentimientos corresponden a intereses extrapatrimoniales y por tanto, corresponde indemnizarlos como daño moral, y no como daño emergente.

Una vez despejado que los sentimientos de compañía y seguridad se indemnizan como daño moral y no emergente, la situación puede subdividirse en dos. Aquel que pagó un precio por la mascota y aquel que no. En la primera situación, el dueño podrá reclamar como daño emergente el precio pagado. Por el contrario, si el dueño adoptó la mascota, o no realizó pago alguno, tendrá que presentar medios de prueba que den cuenta del valor que podría tener su mascota en el mercado, para efectos de identificar el valor del empobrecimiento. El hecho de no haber pagado nada por la mascota, no implica que su patrimonio no se haya empobrecido, el empobrecimiento existe de todas formas.

Segundo, podría presentarse el caso del dueño que tiene una mascota excepcionalmente talentosa. Es imaginable la situación en virtud de la cual una mascota que provee compañía y seguridad también pueda servir para que el dueño se lucre con ella. Por ello, cabría distinguir entre dos situaciones. El talento de la mascota pue- 
de corresponder a una habilidad que puede reportarle ganancias económicas, como sería el caso de un perro que realiza acrobacias en concursos, o por otra parte, el talento de la mascota radica en habilidades que solo le proveen beneficios a su dueño específico o a un limitado número de personas y que no son estrictamente económicos, por ejemplo, los perros lazarillos que guían a personas no videntes. Si lo que se pretende es distinguir exclusivamente el valor económico de las mascotas, no cabe duda que estas valen más que otras en el mercado. En el primer caso es indispensable distinguir entre el daño emergente y el lucro cesante. Una cosa es lo que vale la mascota talentosa en sí misma y otra cosa lo que el dueño dejó de obtener en virtud de un daño en ella. Despejado aquello, valorizar a una mascota talentosa se presenta como una actividad compleja. En mi parecer ya no existirá la diferencia entre una mascota comprada y una adoptada, ya que ahora ambas mascotas valen por su talento y no por su valor base de mercado. O en otros términos, no es comparable el valor de una mascota sin talento con una con talento, cualquiera sea su especie y raza. Es perfectamente imaginable que un "quiltro" adoptado de la calle tenga habilidades especiales valoradas en ciertos negocios y aquello implique que su valor de mercado sea superior, inclusive, al de perros de raza sin talento. Si aquellos no tuvieran ninguna habilidad, probablemente el segundo sería considerado más valioso que el primero. No es ese el caso. Si no existen otros antecedentes, tal parece que podría recurrirse a parámetros establecidos dentro del negocio específico en que se desarrolla el talento de la mascota, y partir de allí generar un promedio de valorización pecuniaria, el cual por supuesto, nunca estará exento de polémicas. Desde luego, lo razonable sería esperar que el valor de una mascota con talento sea superior a su propio valor base de mercado, por ejemplo, un pastor alemán que no tiene aptitudes para concursos tendrá un valor en el mercado, pero en caso de dedicarse a dicha actividad, lo esperable es que su valor de mercado sea superior al del que no la desarrolla.

Como se dijo, en los casos antes mencionados la mascota termina muerta o extraviada, pero ¿Qué ocurre con aquellas mascotas que tan solo quedan severamente dañadas? De acuerdo a Barros, según lo manifestado anteriormente, si las mascotas estrictamente son cosas, y la cosa resultó dañada, también podría demandarse el daño emergente derivado de que la mascota, ahora dañada y defectuosa, vale menos. A esta situación se le aplican los problemas antes vistos en caso de que la mascota termine muerta o extraviada. Por ende, tan solo será daño emergente el empobrecimiento del dueño valorizado en función del precio base del valor de mercado y aquel menoscabo producido porque la mascota dañada ha perdido el talento que la hacía valiosa.

Podría argumentarse que en el caso de que la mascota termine tan solo dañada, pero no muerta ni extraviada, el daño emergente podría ser aquel que resulta de los gastos veterinarios para su curación. De ser así, sería irrelevante si entre el dueño y quien dañó a la mascota existió contrato o no. Sin embargo, esta solución no aplicaría 
a los dos casos antes mencionados. Puede presentarse como una solución idónea para aquel dueño que valoriza a su mascota bajo estrictos estándares de mercado. Si con los gastos veterinarios su mascota resulta totalmente curada, y por tanto, termina valiendo lo mismo que antes del daño, entonces su disminución patrimonial puede coincidir con el valor de dichos gastos.

Sin embargo, en el caso de mascotas talentosas, puede presentarse el problema de que si bien la mascota puede sanarse de sus daños, tal vez no quede en condiciones de ejecutar el talento que la hacía particularmente valiosa. En dicho caso, los gastos veterinarios pueden resultar ser ostensiblemente inferiores a la pérdida de valor de la mascota en su mercado específico, y por tanto, el daño emergente no se ajustará exactamente al valor de los gastos veterinarios.

Se ha dicho que teóricamente el daño emergente no debería presentar dificultades $^{6}$, pero el daño en mascotas se presenta como un caso desafiante, puesto que implica valorizar pecuniariamente a bienes extrapatrimoniales con valor de afección. Inclusive mencionar que una mascota pueda resultar "defectuosa" a producto de un daño, suena incómodo conceptualmente. Sin embargo, valorizarlas económicamente bajo criterios de mercado no debiese resultar imposible toda vez que las mascotas son bienes, guste o no.

En el caso en comento se puede identificar con claridad la dificultad de avaluación del daño emergente. De partida, la dueña no valorizó a Tony en sí mismo como una cosa, presumiblemente por que no pudo concebirlo como un bien con valor de mercado sino como un bien con valor de afección y el valor de la cosa se mezcló indistinguiblemente con valores morales ligados a ella. Cabe recordar que Tony tenía un arraigo familiar especial, atendido a que fue un regalo de su marido ahora fallecido. Por ello, el daño emergente se valorizó en base, únicamente, a los gastos del servicio de guardería objeto del contrato incumplido. Sin embargo, de acuerdo a lo expuesto aquí, no era del todo imposible que la demandante valorizara a su gato como una cosa con valor económico y en virtud de aquel, reclamar un daño emergente por un monto ascendente a su valor de mercado, indicando que el extravío de su gato significó un empobrecimiento de su patrimonio, toda vez que existe una diferencia en el activo de su patrimonio ${ }^{7}$ entre su valor original y el valor posterior al incumplimiento.

En suma, las mascotas pueden ser consideradas bienes con valor de afección para su dueño y un daño en ellos podría significar un incumplimiento contractual en caso de existir contrato entre las partes, como ocurrió en el caso en comento. Si la mascota resulta muerta, extraviada o dañada, aquello puede significar un daño tanto patrimonial como extrapatrimonial, pero como pudo observarse, en estos casos el daño

$\overline{\text { 6. DOMÍNGUEZ (2010) p. } 11 .}$

7. BAEZA (2011) p. 138. 
patrimonial será marginal en comparación con el extrapatrimonial. Si bien aquí se han presentado ciertos parámetros que podrían resultar útiles para distinguir el daño emergente del daño moral al momento de valorizar pecuniariamente a una mascota, atendida la existencia de casos disimiles, dichos parámetros no son nítidos ni uniformes. Con todo, teóricamente debiese ser posible avaluar pecuniariamente a una mascota y distinguir su valor de mercado de los sentimientos de afección hacia ella, los que siempre podrán ser indemnizados bajo el rubro del daño moral. Y a medida que la sociedad incremente la valoración social que tienen las mascotas y animales de compañía, no sería extraño que los tribunales comiencen a recibir más casos como el del gato Tony.

\section{Referencias bibliográficas}

BAEZA OVALLE, José Gonzalo (2011): “Extensión moral del patrimonio”. En Revista Ars Boni Et Aequi, Universidad Bernardo O’Higgins, Vol. 7, № 1 , pp. 135-156.

BARROS BOURIE, Enrique (2006): Tratado de responsabilidad extracontractual (Santiago de Chile, Editorial Jurídica de Chile).

DOMÍNGUEZ ÁGUILA, Ramón (2010): "Los límites al principio de reparación integral". En Revista Chilena de Derecho Privado, Fundación Fernando Fueyo, ํㅜㄷㅗ. pp. 9-28.

SALINAS UGARTE, Gastón (2011): Responsabilidad civil contractual (Tomo I) (Santiago de Chile, Legal Publishing).

STITCHKIN BRANOVER, David (1961): "Los bienes extrapatrimonial". Revista de Derecho, Universidad de Concepción, N ${ }^{\circ} 115$, Año XXIX, pp. 3-29. 